Enferm Bras 2019;18(2);314-8

https://doi.org/10.33233/eb.v18i2.1318

\title{
RELATO DE EXPERIÊNCIA \\ Contribuições da monitoria acadêmica em urgência, emergência e terapia intensiva para enfermagem
}

Ionara da Silva*, Joyce Carolynne Silva*, Karen Rayara Bezerra Lima*, Daniele Vieira Dantas, D,Sc. ${ }^{* \star}$, Rodrigo Assis Neves Dantas, D.Sc. ${ }^{* \star}$, Maria do Carmo de Oliveira Ribeiro, D.Sc. ${ }^{* \star *}$

*Discente do curso de Enfermagem da Universidade Federal do Rio Grande do Norte (UFRN), Natal/RN, ${ }^{* *}$ Enfermeira pela UFRN, Natal/RN, ${ }^{* * * E n f e r m e i r o, ~ D o c e n t e ~ d o ~ D e p a r t a m e n t o ~ d e ~}$ Enfermagem da UFRN, Natal/RN, ${ }^{* * * * E n f e r m e i r a, ~ P r o f e s s o r a ~ A d j u n t a ~ d o ~ D e p a r t a m e n t o ~ d e ~}$ Enfermagem da Universidade Federal de Sergipe/UFS, Aracajú/SE

Recebido em 13 de novembro de 2017; aceito em 20 de novembro de 2018.

Endereço de correspondência: Rodrigo Assis Neves Dantas, Rua Petra Kelly, 61, Geraldo Galvão Residencial, casa 48 Nova Parnamirim 59152-330 Parnamirim RN, E-mail: rodrigoenf@yahoo.com.br; Ionara da Silva: ionarasilva13@gmail.com; Joyce Carolynne Silva: joyceecarol@gmail.com; Karen Rayara Bezerra Lima: karen_rayara@hotmail.com; Daniele Vieira Dantas: daniele00@hotmail.com; Maria do Carmo de Oliveira Ribeiro: enffer2@gmail.com

\begin{abstract}
Resumo
Objetivo: Descrever a vivência durante a monitoria da disciplina de alta complexidade da graduação em Enfermagem, no cuidado ao paciente crítico atendido em emergência e terapia intensiva. Métodos: Trata-se de um estudo descritivo, do tipo relato de experiência, realizado no primeiro semestre de 2017 pelas monitoras do projeto de ensino intitulado "Inovando o processo de ensino-aprendizagem em Enfermagem na urgência e emergência e terapia intensiva", tendo como público-alvo discentes do sexto período do curso de graduação em Enfermagem. Resultados: O papel das monitoras foi, através da divisão da turma em trios, simular o Objective Structured Clinical Examination (OSCE) utilizando um caso clínico de Parada Cardiorrespiratória (PCR), e assim estimular os estudantes a praticar de forma realística as manobras de reanimação cardiopulmonar, além de utilizar o raciocínio clínico e julgamento crítico para definir a possível causa da parada, bem como os cuidados pós-reanimação. Conclusão: A experiência da monitoria é de suma importância na formação acadêmica, pois, ao passo em que utiliza metodologias ativas com a finalidade de garantir melhorias no processo de ensino e aprendizagem dos alunos, o monitor também obtém extensa carga de conhecimentos na área e torna-se sujeito ativo no processo de iniciação à docência.
\end{abstract}

Palavras-chave: ensino, estudantes de enfermagem, reanimação cardiopulmonar, cuidados críticos.

\section{Abstract \\ Contributions of the academic monitors of urgency, emergency and intensive care for nursing}

Objective: To describe the experience during the monitoring of the discipline of high complexity of Nursing graduation, in the critical patient care attended in emergency and intensive care. Methods: This is a descriptive study, experience report type, carried out in the first semester of 2017 by the instructors of the project entitled "Innovating the teaching-learning process in Nursing in emergency and intensive care", taking as the target audience of the sixth period of undergraduate nursing course. Results: The role of the monitors was to simulate the Objective Structured Clinical Examination (OSCE) using a clinical case of Cardiopulmonary Arrest (CPR), through the division of the class into trios, and thus to encourage students to realistically practice Cardiopulmonary Resuscitation maneuvers, in addition to using the clinical reasoning and critical judgment to define the possible cause of parturition, as well as post-resuscitation care. Conclusion: The monitoring experience is of paramount importance in academic training, because, while using active methodologies with the purpose of guaranteeing improvements in the teaching and 
learning process of the students, the monitor also obtains an extensive knowledge in the area and becomes an active subject in the process of initiation to teaching.

Key-words: teaching, students, nursing, cardiopulmonary resuscitation, critical care.

\section{Resumen}

Contribuciones del monitoreo académico en urgencia, emergencia y terapia intensiva para enfermería

Objetivo: Describir la vivencia durante el monitoreo de la asignatura de alta complejidad de la graduación en Enfermería, en el cuidado al paciente crítico atendido en emergencia y terapia intensiva. Métodos: Se trata de un estudio descriptivo, del tipo de relato de experiencia, realizado en el primer semestre de 2017 por los monitores del proyecto de enseñanza titulado "Innovando el proceso de enseñanza-aprendizaje en Enfermería en urgencia y emergencia y terapia intensiva", teniendo como público destinatario discentes del sexto período del curso de graduación en Enfermería. Resultados: El papel de los monitores fue, a través de la división de la clase en tríos, simular el Objective Structured Clinical Examination (OSCE) utilizando un caso clínico de Parada Cardiorrespiratoria (PCR), y así estimular a los estudiantes a practicar de forma realista las maniobras de reanimación cardiopulmonar, raciocinio clínico y juicio crítico para definir la posible causa de la parada, así como los cuidados post reanimación. Conclusión: La experiencia del monitoreo es de suma importancia en la formación académica, pues, al paso que utiliza metodologías activas con la finalidad de garantizar mejoras en el proceso de enseñanza y aprendizaje de los alumnos, el monitor también obtiene una extensa carga de conocimientos en el área y se torna sujeto activo en el proceso de iniciación a la docencia.

Palabras-clave: enseñanza, estudiantes de enfermería, reanimación cardiopulmonar, cuidados críticos.

Introdução

Embora os termos "Urgência" e "Emergência" sejam frequentemente confundidos, possuem diferenças. A urgência caracteriza-se pelo surgimento inesperado de um agravo à saúde com ou sem risco a vida, enquanto a emergência é um agravo esperado e com risco iminente à vida. Por outro lado, ambos indicam noção de pressa, necessitando de atenção profissional imediata [1].

$O$ atendimento a situações de urgência e emergência é realizado preferencialmente no Pronto-Socorro (PS) ou em Unidades de Pronto Atendimento (UPA), porém, outros serviços como Unidades Básicas de Saúde devem estar preparados para intervir nesses casos, protocolando a assistência, mantendo a estrutura necessária e a educação permanente de seus profissionais, pois se tem visto que alguns destes tendem a encaminhar o paciente para unidades de maior complexidade antes de realizar uma avaliação prévia ou estabilização do quadro clínico $[2,3]$.

É imprescindível que os profissionais envolvidos nessa assistência mantenham tranquilidade e ao mesmo tempo agilidade associada à tomada de decisões rápidas e seguras. Para tanto, torna-se necessário conhecimento científico e experiência prática, além do uso de ferramentas como capacitações e implementação de protocolos $[4,5]$.

A experiência prática pode ser iniciada na graduação, por meio de simulações, tendo em vista que testes escritos não são capazes de garantir totalmente a competência do discente, a qualidade da sua assistência e a segurança de pacientes críticos. As simulações são importantes durante o processo de ensino, pois além de melhorar o conhecimento e as habilidades psicomotoras e cognitivas, incentivam a comunicação entre a equipe envolvida no cuidado em um ambiente bem próximo da realidade e permite a análise do desempenho individual [6].

Tendo em vista a necessidade da obtenção de experiência prática pelos profissionais de saúde, ainda na graduação, como citado acima, além da importância de compartilhar experiências educacionais que demonstram eficácia, o presente trabalho tem o objetivo de descrever a vivência durante a monitoria da disciplina de alta complexidade da graduação em Enfermagem, no cuidado ao paciente crítico atendido em emergência e terapia intensiva.

Material e métodos

Trata-se de um estudo descritivo do tipo relato de experiência vivenciado pelas Monitoras do projeto de ensino intitulado "Inovando o processo de ensino-aprendizagem em Enfermagem 
na urgência e emergência e terapia intensiva" da Universidade Federal do Rio Grande do Norte (UFRN).

Feito de modo contextualizado, com objetividade e aporte teórico, o relato de experiência diz respeito a um texto cuja função social é relatar uma experiência vivida, trazendo considerações significativas sobre a experiência [7].

As atividades, que consistiram em ações desenvolvidas em sala de aula, apoio pedagógico aos discentes e aulas práticas no laboratório de habilidades clínicas, foram realizadas com os acadêmicos de Enfermagem do sexto período da UFRN, no período de 01 de março a 31 de junho de 2017, os quais estavam cursando a disciplina Atenção Integral à Saúde II: Módulo de Alta Complexidade.

As monitorias aconteciam semanalmente, sendo necessário um agendamento prévio por parte dos discentes interessados, com, no mínimo, 3 horas de antecedência para plantões de dúvidas e 24 horas em casos de treinamentos práticos em laboratório. A duração de cada plantão variava de acordo com a necessidade dos alunos monitorados e a disponibilidade das monitoras.

Além dos relatos das experiências vivenciadas pelas monitoras, o presente trabalho também utilizou como base alguns artigos que se encontram disponíveis no Portal de Periódicos da Capes, elaborados entre os anos de 2013 e 2017, e protocolos relacionados ao atendimento em casos de parada cardiorrespiratória.

Resultados

O projeto de monitoria "Inovando o processo de ensino-aprendizagem em Enfermagem na urgência e emergência e terapia intensiva" visa estimular a implantação de metodologias ativas e criativas no processo de ensino-aprendizagem dos acadêmicos. Entre as metodologias existentes, a simulação realística em laboratório de habilidades, com ênfase na técnica de Objective Structured Clinical Examination (OSCE), foi a forma adotada para melhor mensurar as habilidades e competências dos discentes.

Por ser a monitoria um meio de apoio para a disciplina de Alta Complexidade, os plantões de dúvidas visavam à elucidação de alguns questionamentos e dificuldades por parte dos alunos relacionados à assistência de enfermagem à pacientes em situações de urgências e emergências clínicas e extra-hospitalares, tais como: distúrbios metabólicos, do trato urinário, emergências neurológicas, respiratórias, gastrintestinais, cardiovasculares e hemodinâmicas, parada cardiorrespiratória (PCR), traumas, entre outros. Por sua vez, os treinamentos práticos em laboratório davam maior enfoque à prática de Reanimação Cardiopulmonar (RCP), utilizando como base para as ações o protocolo de RCP estabelecido pela American Heart Association (AHA) de 2015.

Nesse sentido, o papel das monitoras foi, através da divisão da turma em trios, simular - OSCE utilizando um caso clínico de Parada Cardiorrespiratória (PCR), e assim estimular os estudantes a praticar de forma realística as manobras de Reanimação Cardiorrespiratória, além de utilizar o raciocínio clínico e julgamento crítico para definir a possível causa da parada, bem como os cuidados pós-reanimação.

Como instrumento metodológico para execução do OSCE, utilizou-se o Procedimento/Protocolo Operacional Padrão (POP), que discrimina o passo a passo sequencial que o estudante deve realizar.

Apesar da deficiência de certos insumos e equipamentos no laboratório de habilidades clínicas, buscou-se ao máximo aproximar o cenário de práticas com a realidade hospitalar, para tanto, foram utilizadas camas hospitalares com manequim Resusci Anne, carrinho de emergência devidamente equipado, materiais próprios para punção venosa, suporte de soro com soluções fisiológicas, biombos e escada auxiliar para maca.

Durante o semestre notou-se grande adesão dos discentes às monitorias, principalmente durante os plantões de atividades práticas e, ao final, o desempenho destes no OSCE foi muito satisfatório.

Discussão

Dentre todas as emergências, a parada cardiorrespiratória se caracteriza como a mais temida, uma vez que as chances de sobrevivência são diretamente proporcionais a um atendimento rápido, seguro e de qualidade [8]. Esta se caracteriza por cessação brusca e súbita da circulação sistêmica e respiração. Um indivíduo em PCR apresenta inconsciência, ausência de respiração e pulso. Suas possíveis causas estão divididas em 5Hs e 5Ts: Hipóxia, 
Hipovolemia, Hidrogênio (acidose), Hiper/Hipocalemia, Hipotermia; Tóxicos, Tamponamento cardíaco, Tensão no tórax (pneumotórax hipertensivo), Trombose coronária (infarto agudo do miocárdio), Tromboembolismo pulmonar [9].

Uma RCP bem-sucedida depende de uma sequência de procedimentos que pode ser sistematizada no conceito de corrente de sobrevivência [9]. Portanto, faz-se necessário que os enfermeiros em formação recebam boa capacitação para agir com segurança quando se depararem com uma situação de PCR e assim garantir, quando possível, o retorno espontâneo da circulação sem consequências graves ao sistema neurológico.

É inegável que as monitorias acadêmicas trazem inúmeras vantagens, tanto para o discente que recebe o apoio pedagógico, quanto para os próprios monitores, uma vez que, antes de cada plantão de dúvidas e práticas agendadas, as monitoras realizavam revisão dos assuntos abordados, buscando sempre a leitura de artigos científicos atuais, além de estudos de casos, para que houvesse uma apropriação maior do tema. Com isso, ao "ensinar" também adquiriam conhecimentos.

Sendo assim, as vantagens perpassam a obtenção de um título, pois as monitorias também contribuem para o ganho intelectual do monitor através do apoio dado aos acadêmicos, bem como através da relação interpessoal de troca de conhecimentos com os docentes orientadores [10]. Além disso, a monitoria proporciona ao discente monitor uma aproximação com a prática docente, possibilitando-o a aquisição de habilidades inerentes à docência e contribuindo para a formação de profissionais qualificados para exercer a profissão [11].

Para os alunos, percebe-se que a monitoria, ao articular teoria e prática, é de extrema importância em seu processo de ensino-aprendizagem, uma vez que, além de possibilitar que eles esclareçam suas dúvidas e aprimorem seus conhecimentos, ainda os aproxima de equipamentos e materiais utilizados no cuidado ao paciente crítico, familiarizando-os com a realidade e o cotidiano da prática assistencial de enfermagem [11].

Conclusão

A experiência da monitoria é de suma importância na formação acadêmica, pois, ao passo em que utiliza metodologias ativas com a finalidade de garantir melhorias no processo de ensino e aprendizagem dos alunos, propiciando a estes o desenvolvimento de habilidades e competências técnicas necessárias à assistência a pacientes críticos, o monitor também obtém extensa carga de conhecimentos na área e torna-se sujeito ativo no processo de iniciação à docência.

Sendo assim, torna-se de extrema importância o desenvolvimento de novas técnicas de ensino-aprendizagem, enfocando novas metodologias, como o Objective Structured Clinical Examination.

1. Romani HM, Sperandio JA, Sperandio JL, Diniz MN, Inácio MAM. Uma visão assistencial da urgência e emergência no sistema de saúde. Rev Bioet 2009;17(1):4153.

2. Diniz AMO. Construção de protocolo clínico de atendimento de enfermagem em urgência e emergência no município de Piedade dos Gerais/MG [Monografia]. Florianópolis: Universidade Federal de Santa Catarina, Curso de especialização em linhas de cuidado em enfermagem - opção urgência e emergência, Departamento de Enfermagem; 2014.

3. Silva VMS. A importância da capacitação no atendimento a parada cardiorrespiratória da equipe de uma unidade básica de saúde [Monografia]. Florianópolis: Universidade Federal de Santa Catarina, Curso de especialização em linhas de cuidado em enfermagem - opção urgência e emergência, Departamento de Enfermagem; 2014.

4. Souza MJ. Proposta de capacitação para profissionais de enfermagem da urgência e emergência de um hospital público [Monografia]. Florianópolis: Universidade Federal de Santa Catarina, Curso de especialização em linhas de cuidado em enfermagem opção urgência e emergência, Departamento de Enfermagem; 2014.

5. Ferreira CE. Projeto de intervenção: capacitar os profissionais de nível médio e superior de enfermagem do Hospital Municipal Nossa Senhora da Penha de Conceição do Castelo de atendimento de urgência e emergência no extra e intra-hospitalar [Monografia]. Florianópolis: Universidade Federal de Santa Catarina, Curso de 
especialização em linhas de cuidado em enfermagem - opção urgência e emergência, Departamento de Enfermagem; 2014.

6. Guedes MHC, Gomes JTS, Almeida ASR, Bonfim ALDL, Vilela LFF, Côrtes PPR. Uso de simulação no ensino de urgência e emergência pré-hospitalar para discentes de medicina: Relato de experiência. Revista de Saúde 2017;8(1):8-14.

7. Lima KRBL, Brito TA, Nunes HMA, Rodriguez GCB, Nascimento RA, Henriques LMN, et al. Nursing students experience in emergency and intensive care in a reference hospital. International Archives of Medicine 2016;287(9):1-5.

https://doi.org/10.3823/2158

8. Alves CA, Barbosa, CNS, Faria, HTG. Parada cardiorrespiratória e enfermagem: 0 conhecimento acerca do suporte básico de vida. Cogitare Enferm 2013;18(2):296-301. https://doi.org/10.5380/ce.v18i2.32579

9. Gonzalez MM, Timmerman S, Oliveira RG, Facholi T, Dallan LAP, Araújo S et al. Diretriz de Ressuscitação Cardiopulmonar e Cuidados Cardiovasculares de Emergência da Sociedade Brasileira de Cardiologia: Resumo Executivo. Arq Bras Cardiol 2013;100 (2):105-13.

10. Matoso LML. A importância da monitoria na formação acadêmica do monitor: um relato de experiência. Catussaba 2014;3(2):77-83.

11. Ascari RA, Mahle M. Vivências da monitoria na disciplina de enfermagem no cuidado perioperatório: relato de experiência em 2015.1. In: Universidade do Estado de Santa Catarina. 25ำ seminário de iniciação científica; 2015. 